\title{
BIBLIOTECA UNIVERSITÁRIA, UM AMBIENTE SISTÊMICO PROPÍCIO AO ACESSO, AO USO E À APROPRIAÇÃO DA INFORMAÇÃO: contribuições da web social para esse ambiente
}

\author{
Raquel Rosário Santos \\ Doutora em Ciência da Informação \\ pela Universidade Federal da Paraíba. \\ E-mail: quelrosario@gmail.com \\ Emeide Nóbrega Duarte \\ Professora do Departamento de \\ Ciência da Informação da Universidade \\ Federal da Paraíba. \\ E-mail: emeide@hotmail.com
}

\begin{abstract}
RESUMO
O presente artigo registra uma reflexão sobre a biblioteca universitária, enquanto ambiente sistêmico, que potencializa, por meio de suas atividades de mediação, o acesso, o uso e a apropriação da informação. É discutido o processo de utilização dos dispositivos de comunicação na web social, a fim de proporcionar a criação de novos conhecimentos pelos usuários da informação. Nessa perspectiva, objetiva-se com este artigo de aporte teórico, contextualizar as contribuições dos dispositivos de comunicação da web social no desenvolvimento das atividades para construção de conhecimento no ambiente da biblioteca universitária.
\end{abstract}

Palavras-chave: Biblioteca Universitária. Bibliotecários. Dispositivos de comunicação da web social.

\section{LIBRARY UNIVERSITY A SYSTEMIC \\ ENABLING ENVIRONMENT TO ACCESS, USE AND OWNERSHIP OF INFORMATION: social web contributions to this environment}

Keywords: University Library. Librarians. Social web. 


\section{INTRODUÇÃO}

Para que a biblioteca universitária possa ser reconhecida como um ambiente que propicia a construção do conhecimento e favorece o crescimento social, cultural e cognitivo dos sujeitos, os bibliotecários, gestores ou agentes da mediação da informação que nela atuam devem assumir o compromisso e a responsabilidade de adotar os recursos necessários, sejam eles técnicos, tecnológicos e/ou metodológicos. É imprescindível que os bibliotecários ampliem suas atividades de mediação da informação, de modo a ultrapassar os "muros" das Instituições de Ensino Superior (IES), anular as barreiras de espaço e de tempo e auxiliar o processo de disseminação, uso e apropriação de informações.

Nos últimos anos, os dispositivos de comunicação da web social vêm fomentando a ampliação de uma cultura participativa, da troca e da interlocução de informações entre os sujeitos, que tem provocado mudanças também no modo como os bibliotecários e os usuários se comunicam. Assim, se o bibliotecário adotar esses dispositivos de comunicação da web social, ele poderá realizar suas atividades de mediação da informação para um número maior de sujeitos e ampliar o processo de transmissão de informações, tendo um aliado para a construção de redes de conhecimento a partir do ambiente da biblioteca universitária.

Para que o bibliotecário possa utilizar e explorar os recursos na web e os dispositivos de comunicação da web social, é relevante sistematizar suas atividades e ampliar seus objetivos e metas. Esse profissional não pode trabalhar de modo inconsciente, visto que há benefícios adquiridos com a utilização dos dispositivos de comunicação da web social para aproximar os usuários, apresentar informações sobre o acervo e o ambiente físico da biblioteca universitária e alternativas de contato e interação que possam responder a questionamentos e indicar problemas ou sugestões. Assim, é importante que o bibliotecário atue de maneira estratégica, gerencie suas atividades de mediação da informação também nesses dispositivos de comunicação e passe a utilizá-los para que os sujeitos tenham conforto no acesso à informação.

A partir do exposto, apresenta-se uma discussão sobre o desenvolvimento de estudos realizados nos últimos anos. 0 ambiente da biblioteca universitária é o universo pesquisado, analisando as possibilidades de se intensificar o uso dos dispositivos de 
comunicação da web social e da possibilidade de ampliar as atividades de mediação da informação.

\section{A BIBLIOTECA UNIVERSITÁRIA: UM SISTEMA PARA CONSTRUÇÃO DO CONHECIMENTO}

Desde sua origem, a biblioteca tem uma missão muito específica relacionada à guarda e à preservação do registro do conhecimento humano. A memória da humanidade, registrada em materiais informacionais presentes nos acervos das bibliotecas, ao ser passada de geração para geração, pode favorecer novas descobertas e proporcionar uma constante evolução. Rodrigues e colaboradores (2013, p.83) afirmam que "[...] a importância da biblioteca para a preservação e conservação do conhecimento é inquestionável, pois desde o início da humanidade o homem se preocupa em registrar o conhecimento por ele produzido." Assim, a biblioteca tem o papel basilar de contribuir com para a perpetuação e a continuidade do desenvolvimento humano, por meio do registro do conhecimento, e de transmitir e comunicar ao presente as grandes conquistas alcançadas no passado.

Ressalte-se, no entanto, que, para se produzir o conhecimento humano, preservar e guardar não é o bastante. Essas atividades não se encerram em si mesmas, mas se completam e correlacionam-se com a organização, a representação, a disseminação e o acesso aos materiais informacionais. A missão da biblioteca é de preservar para proporcionar o acesso, o uso e a geração do conhecimento humano. Bufrem e Sorribas (2008, p.70, destaque das autoras) enunciam que “[...] as bibliotecas universitárias não se constituem apenas em guardiãs, difusoras ou disseminadoras do saber, pois seus compromissos ampliam-se, abrangendo o aprender e o criar." As autoras destacam uma contribuição ainda maior da biblioteca: seu compromisso com o desenvolvimento dos usuários em contribuir com o seu aprendizado. Assim, quando o usuário aprende a utilizar os serviços e os produtos de que a biblioteca dispõe, de maneira eficiente, poderá adquirir uma visão diferente do "mundo", analisar criticamente a realidade social e atuar como agente de mudanças sociais, ampliando seus conhecimentos culturais e profissionais.

A biblioteca universitária, como um ambiente que aproxima o sujeito social da informação, pode esclarecer dúvidas sobre os fenômenos que cercam os sujeitos; promover a apropriação de novas informações; ampliar e desenvolver novos 
conhecimentos e auxiliar os sujeitos a desempenharem um papel de relevância e participação ativa em qualquer ambiente social a que pertençam. Ao refletir sobre as atividades que podem ser realizadas pela biblioteca universitária como um ambiente de construção do conhecimento, percebe-se que existe outra particularidade, um elemento que também a define. Trata-se da ligação e da subordinação a uma instituição maior - a universidade. "Considerando a biblioteca universitária dentro do seu contexto mais amplo - a Universidade ou a Instituição de Ensino Superior - é importante compreender que sua atuação não poderá estar desvinculada do meio-ambiente acadêmico e sua cultura." (FUJITA, 2005, p.99).

A cultura, a sociedade e o meio acadêmico são três elementos que, segundo Fujita (2005), integram a biblioteca universitária e interferem diretamente em seu funcionamento, seja ao traçar seus objetivos para o estabelecimento de sua missão ou em relação aos aspectos mais tangíveis, como aquisição de documentos e equipamentos. Essa reflexão se aproxima da afirmação apresentada por Shera (1973, tradução nossa), quanto à missão da biblioteca, que é de maximizar a utilidade social de registros gráficos para o benefício do indivíduo e da sociedade.

Como um ambiente social, a biblioteca recebe influência direta do meio em que está inserida - social, cultural, econômica e/ou política. A biblioteca universitária é, portanto, um espelho das inquietações e das ansiedades da sociedade. Conforme Fujita (2005, p.101), “[...] a biblioteca universitária insere-se em um contexto universitário cujos objetivos maiores são o desenvolvimento educacional, social, político e econômico da sociedade humana." Apesar de sua especificidade, as bibliotecas universitárias também recebem influência, tanto da instituição de ensino superior à qual estão vinculadas, quanto das mudanças que ocorrem no sistema educacional, político, econômico e social.

Em tempos históricos distintos, a biblioteca universitária representou, com afinco, seu papel de guardiã do conhecimento registrado. Durante muito tempo, seu foco foram atividades como preservação, organização e representação, refletindo a dinâmica social. As bibliotecas, conforme Shera (1973, tradução nossa), foram criadas - e mantidas assim por séculos - como depósitos da transcrição de sua cultura. Por outro lado, nos tempos atuais, as preocupações dos organismos governamentais e das instituições educativas diferem da antiga imagem da biblioteca universitária e rompem com ela. Sua preocupação volta-se para o crescimento cultural, cognitivo e econômico dos sujeitos; a necessidade de desenvolver, nos futuros profissionais das diversas áreas, competências e 
comportamento informacional, entre as múltiplas e distintas habilidades exigidas. A biblioteca apresenta-se como reflexo da sociedade, que, de acordo com Shera (1973, tradução nossa), tornou-se um agente da democracia e ampliou sua influência até para os não privilegiados e socialmente em desvantagem.

A universidade é uma instituição cujo objetivo central é o de formar profissionais por meio do ensino e da pesquisa. A partir do ensino-aprendizagem, os sujeitos ampliam seus conhecimentos, formam seus acervos mentais e desenvolvem conhecimentos específicos da área em que atuarão como profissionais. Nesse sentido, vejam-se estas palavras de Gomes (2000, p. 63):

Os sujeitos ligados ao ensino-aprendizagem estabelecem entre si um processo de interação, que também envolve suas práticas comunicativas realizadas com o apoio dos diversos recursos tecnológicos. Nesse processo, constroem seus modelos mentais que permitem a mediação entre o 'mundo interior' e o 'mundo exterior', possibilitando assim a construção de seus conhecimentos.

$\mathrm{Na}$ perspectiva da contribuição para o ensino-aprendizagem, a biblioteca universitária é parte fundamental, pois, por meio dos seus produtos e serviços, permite que o usuário tenha acesso à informação que está registrada e que representa o conhecimento consolidado e aceito pela comunidade científica. Isso facilita ao usuário desenvolver suas reflexões e debater sobre os temas no interior de grupos de estudo e pesquisa. Com o acesso a essa biblioteca, os sujeitos podem continuar seu processo de aprendizagem, que se inicia com a exposição de um tema em sala.

A pesquisa é outro processo desenvolvido pela universidade, com vistas à construção de novos conhecimentos. Segundo Fujita (2005, p.99), “[...] a Universidade promove a construção de conhecimento através da pesquisa, e realiza, por meio dos conteúdos curriculares, o contato do aluno com o conhecimento já construído." Toda atividade desenvolvida pela universidade está interligada, como se pode visualizar na Figura 1. 0 ensino e a pesquisa contribuem mutuamente. Isso quer dizer que o conhecimento apreendido com leituras, exposições e debates em sala de aula é agregado pelo discente e pelo docente e promove reflexão ao tratar sobre temas relacionados ao desenvolvimento de pesquisas científicas. 
Figura 01: Pilares que constituem a universidade

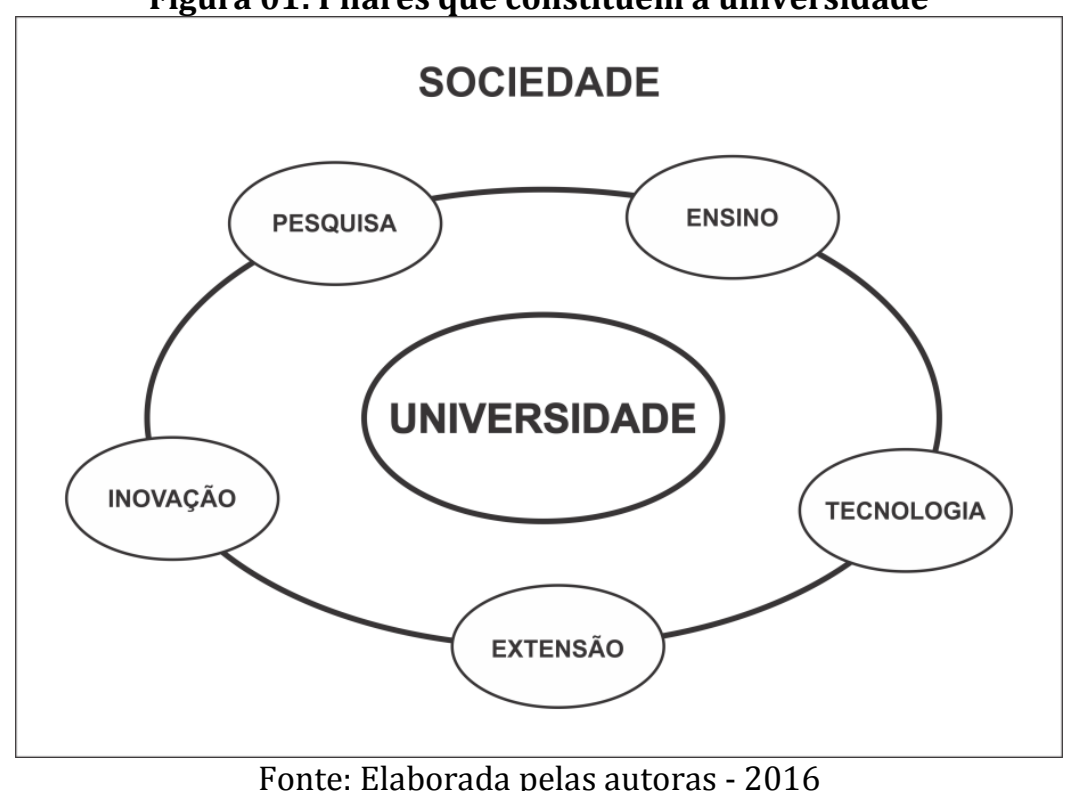

Por meio da pesquisa, o sujeito reflete sobre a área do conhecimento de que faz parte, sobre o objeto de estudo e sobre os fenômenos que envolvem esse objeto. A pesquisa estimula a reflexão, a busca por investigação, o olhar crítico e analítico e, como resultado de toda a investigação, o registro sobre os resultados alcançados. Fujita (2005, p. 99) refere que

A construção de conhecimentos através da pesquisa é, antes de tudo, o pensar de forma crítica e com liberdade acadêmica. 0 conhecimento construído em pesquisa é difundido e ampliado no ensino (e vice-versa) e socializado na extensão, contexto em que novamente receberemos subsídios que impliquem criação de novos conhecimentos.

Fujita (2005) concebe, também, que o conhecimento produzido perpassa todas as atividades desenvolvidas na universidade. Um dos aspectos que pode estar relacionado a essa ação é o trânsito que o sujeito realiza na universidade e as redes sociais que integra. Um sujeito pode ser discente de uma graduação e estar em um grupo de pesquisa, utilizando os mesmos textos e referências para ambas as atividades, participar de um debate em sala de aula, explicitando seu aprendizado para seu grupo de pesquisa e/ou estudo, e elaborar um artigo, que poderá ou não ganhar uma nova dimensão, desde sua utilização pelo docente em sala de aula até a apresentação em eventos acadêmicos. A mesma dinâmica ocorre envolvendo as atividades de extensão, a integração que poderá ocorrer com a pesquisa e o ensino. 
A extensão, por sua vez, é o elemento constitutivo da universidade que mais se aproxima da comunidade. Pode ser entendida como uma interferência e o retorno da universidade para a comunidade, uma vez que ela garante as condições de sua manutenção. 0 conhecimento construído na universidade é transformado em ações aplicáveis à comunidade e que a beneficiem em algum aspecto. Tais ações são referentes à área do conhecimento em que a pesquisa foi produzida. Por outro lado, a extensão também contribui para fortalecer a pesquisa e a área do conhecimento, com novas reflexões e perspectivas que antes não foram percebidas.

A comunicação e a produção do conhecimento são ações de grande importância e que têm relação direta. Quando um sujeito se apropria de uma informação, por meio de uma interação direta com outro ou de um instrumento mediador, como um livro, ele pode socializar, com convicção e segurança, esse novo conhecimento. A significação e o propósito maior da produção e da socialização do conhecimento estão associados à contribuição do crescimento social, especialmente em ambientes de natureza pública, como universidades federais e estaduais, que agregam sujeitos, independentemente de suas origens. Garcia, Almeida Júnior e Valentim (2011, p.352) afirmaram que

\begin{abstract}
As universidades públicas brasileiras têm importante papel no que tange ao desenvolvimento social, político e tecnológico do país. Através do conhecimento por elas construído, essas instituições elaboram e reelaboram ações para a sociedade. É através da mediação da informação que o conhecimento pode ser mediado dentro e fora das universidades, entre seu público especializado e para a sociedade.
\end{abstract}

A universidade e todos os seus recursos e dispositivos de informação contribuem para que o sujeito possa refletir sobre problemas e fenômenos presentes em seu meio, de modo que inferências e/ou soluções possam ser apresentadas ou construídos novos conhecimentos que auxiliem a sociedade. As razões para as quais os sujeitos refletem, criam e registram suas descobertas, experiências e conhecimentos devem estar ligadas a um propósito maior que o de explicitá-los ou materializá-los. 0 objetivo é de contribuir com o desenvolvimento social, transformando as descobertas em produtos e serviços para sociedade e contribuindo para que outros sujeitos possam ampliar seu conhecimento sobre determinado objeto ou fenômeno.

O bibliotecário pode identificar os sujeitos que integram grupos de pesquisa e/ou extensão e tornar evidente a eles seus produtos e serviços, oferecendo serviços 
específicos, por exemplo, alertas dos materiais informacionais que constam no acervo sobre o tema estudado. Raposo e Espírito Santo (2006, p.90) afirmam que, “[...] para fazer jus ao seu papel de espelho da universidade, a biblioteca deve estar sempre atenta para responder com qualidade as demandas informacionais de seus clientes além de, muitas vezes, se adiantar e prover essa demanda." Ao procurar atrair os sujeitos e torná-los usuários reais da biblioteca, eles poderão atuar como multiplicadores, contando os benefícios na utilização da biblioteca aos demais atores das redes da qual fazem parte.

O bibliotecário pode criar estratégias que possam favorecer os sujeitos no processo de ensino-aprendizagem, pesquisa e extensão e contribuir com sua vida social e cultural, haja vista que, em qualquer processo de construção do conhecimento, eles demandam um apoio mais direto da biblioteca. Como afirmam Perrotti e Pieruccini (2007, p.52), “[...] informar e informar-se envolvem saberes e fazeres especiais e especializados que, diferentemente de atitudes, competências e habilidades exigidas em passado culturalmente distinto e cada vez mais distante, dificilmente se constituem no simples fluxo do existir cotidiano." As exigências da própria universidade e dos grupos que esses usuários integram desenvolvem um processo de relação essencial entre eles com a informação, e os sujeitos são cobrados, direta ou indiretamente, para que sejam proficientes no acesso, no uso e na apreensão da informação.

Ao tornar evidente cada atividade/pilar da universidade - ensino, pesquisa e extensão - e a integração entre eles, dois aspectos ficam perceptíveis: o primeiro é de que a universidade é um organismo vivo; o outro, que complementa o primeiro, refere-se ao fato de que a universidade, como organismo, tem várias estruturas que proporcionam o funcionamento dos pilares, como a biblioteca, por exemplo. Essas estruturas se integram e constituem-se sistemicamente, mantendo vivo o organismo. Cada um desses pilares pode ser entendido como um sistema em si, porque são constituídos pelas várias áreas do conhecimento e suas respectivas atividades.

Lima (1998) afirma que um sistema de informação pode ser uma biblioteca, um centro de documentação, um arquivo, um museu ou um banco de dados. Para a autora, seja qual for sua denominação original, um sistema de informação tem a função de coletar, tratar e disseminar a informação produzida pela sociedade e de garantir que parte de seus membros tenha acesso à cultura. Sabendo-se das atividades que a biblioteca realiza tradicionalmente, para guardar, organizar e disseminar a informação, é necessário que ela reflita e se posicione como um sistema de informações. Assim, é relevante que cumpra seu 
papel de procurar se aproximar mais dos usuários, sem limitar o seu fazer à prática pela prática, vise ao benefício social, às mudanças cognitivas e sociais dos usuários e favoreça o desenvolvimento e as condições de proficiência e autonomia dos sujeitos, em relação ao acesso, à utilização e à aplicação das informações.

As atividades desenvolvidas na biblioteca universitária têm uma relação sistêmica, em que uma está diretamente ligada à outra, com o intuito de auxiliar no crescimento cognitivo, social e profissional do usuário. Segundo Fujita (2005, p.98), “[...] a biblioteca universitária é um sistema de informação que é parte de um sistema mais amplo, que poderia ser chamado sistema de informação acadêmico, no qual, a geração de conhecimentos é o objeto da vida universitária." Por meio das ações de mediação da informação realizadas na biblioteca universitária, o usuário pode identificar informações que satisfaçam sua necessidade informacional, esclareçam suas dúvidas e estimulem a criatividade e a criação de ideias, a fim de que o usuário possa produzir e comunicar novos achados e propostas. Nesse processo, cada ação e atividade contribuirão de modo diferente e complementar, em relação à localização, ao acesso à informação, à discussão, à interação sobre essa informação, até a apropriação.

Guinchat e Menou (1992, p.481) afirmam que “[...] o usuário é um elemento fundamental de todos os sistemas de informação, pois a única justificativa das atividades desses sistemas é a transferência de informações entre dois ou mais interlocutores distantes no espaço e no tempo." Dias e Pires (2004, p.11) também ressaltam que o objetivo final de um sistema de informação deve ser pensado em termos do uso dado à informação e dos efeitos resultantes desse uso nas atividades dos usuários. A função mais importante do sistema é, portanto, a forma integrada e articulada com que modifica e interfere na realidade dos sujeitos, fomentando o seu desenvolvimento e a produção de novos conhecimentos.

As atividades realizadas pela biblioteca universitária têm uma forte ligação com o seu objetivo de favorecer o crescimento social e cognitivo dos sujeitos, por meio do acesso, do uso e da forma como esses sujeitos se apropriem da informação. Observa-se a construção de uma dinâmica entre as atividades desenvolvidas pela biblioteca universitária, que, segundo Fujita (2005, p.99, destaque nosso),

[...] é um organismo vivo, um agrupamento de pessoas em permanente interação com atividades específicas, cuja dinâmica utiliza e elabora documentos para registro e difusão do conhecimento em um processo 
cumulativo. Nesse ambiente sabe-se que o principal insumo é o conhecimento e por isso a informação é uma das principais demandas de uma comunidade de pessoas que possuem conhecimento e o compartilham incessantemente para promover a geração de mais conhecimento a ser registrado e divulgado.

Nessa perspectiva, as atividades voltadas para a organização e a representação da informação objetivam ajudar os usuários a identificarem as informações organizadas no acervo das bibliotecas universitárias e terem acesso a elas. Por outro lado, para que, de fato, haja a aproximação entre a informação e o usuário, é essencial o desenvolvimento de atividades como a disseminação da informação, que possibilitam aos usuários estarem cientes das informações que poderão contribuir diretamente para ampliar seu conhecimento e realizar um processo de interlocução mais próxima com os usuários, a fim de solucionar possíveis problemas e diminuir as barreiras de acesso à informação. Somadas com todas as outras atividades desenvolvidas nas bibliotecas universitárias, essas atividades resumem-se em um objetivo - o de atender aos usuários em suas necessidades informacionais e contribuir com a construção de novos conhecimentos.

Um aspecto a ser destacado, a partir da característica sistêmica das atividades realizadas na biblioteca universitária, é a relevância de cada parte do processo, ou seja, a conexão existente entre o sucesso e o insucesso a partir do resultado advindo da atividade anterior. Se uma atividade for executada de maneira inadequada, poderá comprometer as demais e causar prejuízo para o usuário. Por exemplo, se um documento, por algum motivo, deixar de ser indexado corretamente, poderá prejudicar a recuperação da informação, e a busca e o acesso à informação não ocorrerem eficientemente. Consequentemente, a disseminação e a circulação dessa informação ficam comprometidas. É importante que o bibliotecário reflita sobre a integralidade de suas ações e reavalie constantemente suas atividades, de modo a cumprir com eficiência seu papel de auxiliar o sujeito a suprir suas necessidades de informação. Ele também deve auxiliá-lo a desenvolver sua competência em informação, apoiando-o com atividades como realização de oficinas, seminários, debates e palestras sobre temas de interesse de grupos de usuários, entre outras atividades de mediação da informação. Para ele, é um desafio elaborar atividades, produtos e serviços que contribuam para o crescimento do usuário. Sousa e Fujino (2009, p. 1787) afirmam que 
O bibliotecário de referência é um mediador de pesquisas, assim como os docentes, e sua formação como profissional da informação deve objetivar a mudança de condição de um profissional organizador e armazenador de informação para a condição de um profissional criativo, capaz de gerir e compreender as necessidades informacionais de seu público, agregando valor e funcionalidade às informações. Ele assume a posição de um simples orientador na localização de documentos até a de um conselheiro na formulação do foco da pesquisa. (destaque nosso).

O objetivo desse profissional é de auxiliar os usuários a entenderem a complexidade que envolve a informação, compreender a lógica de organização da biblioteca e envolver outros dispositivos de informação, outros ambientes informacionais, sejam físicos ou virtuais, com o fim de esclarecer dúvidas e potencializar a competência e o comportamento informacional, por meio de ações simples, como saber onde buscar as informações e quais as fontes que são confiáveis.

\section{A BIBLIOTECA UNIVERSITÁRIA E A ADOÇÃO DOS DISPOSITIVOS DE COMUNICAÇÃO DA WEB SOCIAL: A BIBLIOTECA PARA ALÉM DE SEUS MUROS FÍSICOS}

A web social oferece recursos para que os sujeitos interajam no ambiente virtual, com mais condições de interlocução, facilita a comunicação e propicia mais dinâmicas através do uso de um conjunto de dispositivos que facilitam o compartilhamento de informações. Curty $(2008$, p.55) afirma que a web pode ser compreendida como

\footnotetext{
Uma web mais social, pois envolve mais pessoas; mais colaborativa, porque todos são partícipes potenciais e têm condição de se envolver mais densamente; mais apreensível, pois desmistifica que conhecimentos técnicos sejam necessários para a interação; uma web que se importa menos com a tecnologia de informação e mais com pessoas, conteúdo e acesso: dizem que por essa Web denota-se a versão 2.0.
}

A web social potencializa a ação ativa por parte dos usuários. 0 bibliotecário pode adotar os recursos que ela oferece, a fim de dinamizar a comunicação com os seus usuários. Blattmann e Silva (2007, p. 197) conceituam a web social como “[...] a construção de espaços para colaboração, interação e participação comunitária tem sido chamada de Web 2.0." Ao adotar esses dispositivos de comunicação da web social, o bibliotecário desenvolve suas ações de mediação, ajuda os usuários a compartilhem informações, atrai 
outros sujeitos que tenham necessidades e interesses comuns e impulsiona a criação e a ampliação de sua rede social, com a finalidade de se apropriar da informação e de adquirir conhecimentos.

Ações de gestão desenvolvidas pelos bibliotecários são essenciais para que a biblioteca universitária possa favorecer a atuação e a colaboração dos usuários, tanto na interação e na socialização de suas experiências e conhecimentos quanto na construção e disponibilização de informações. A “[...] Web 2.0 é um novo espaço para acessar, organizar, gerenciar, tratar e disseminar a informação, conhecimentos e saberes. [...] cabe estudar, experimentar, explorar tecnologias da Web 2.0 para facilitar o acesso e ampliar o uso da informação." (BLATTMANN; SILVA, 2007, p. 211). Então, é imprescindível que a biblioteca sistematize suas atividades de mediação da informação e adote as ações de gestão da informação e do conhecimento.

Apresenta-se o conceito de biblioteca 2.0 como a possibilidade de ampliar para o espaço virtual as atividades de mediação da informação desenvolvidas pela biblioteca. A biblioteca universitária poderá adotar um perfil proativo em relação a uma colaboração mais ativa dos seus usuários, tanto na perspectiva de atender às necessidades individuais de cada sujeito quanto de fortalecer uma participação coletiva, com troca, debate e produção coletiva de ideias e desenvolvimento de atividades.

Se antes a web era estruturada por meio de sites que colocavam todo o conteúdo on-line, de maneira estática, sem oferecer a possibilidade de interação aos internautas, agora é possível criar uma conexão por meio das comunidades de usuários com interesses em comum, resultado do uso da plataforma mais aberta e dinâmica (BLATTMANN; SILVA, 2007, p. 199, destaque nosso).

Os recursos de comunicação na web promovem uma nova maneira de interação os sujeitos podem se comunicar no tempo em que desejarem, independentemente da distância geográfica que podem separá-los fisicamente. Antes de usar esses recursos, o sujeito teria que se deslocar de um espaço geográfico para outro a fim de ver alguém, participar de reuniões ou qualquer outro evento. Com a utilização dos recursos de comunicação e demais aparatos tecnológicos, sem se deslocar, ele pode se comunicar com um amigo ou familiar que reside distante; participar de uma pesquisa ou aplicá-la e participar de uma reunião ou qualquer tipo de evento. Assim, as tecnologias de comunicação rápida, como também é denominada, vêm facilitando a relação entre os 
sujeitos, favorecendo a economia financeira e a física e proporcionando conforto e comodidade para eles.

Comprimimos o tempo e o espaço ao máximo, ao ponto de que, teoricamente, eu posso falar com quem quiser, de onde e para onde quiser, 24 em 24 horas. Por exemplo, cada vez que eu envio um e-mail, em minutos, para todos os meus cerca de 1.800 contactos, estou realmente a atingir uma comunidade alvo que eu fui escolhendo, e muito importante - cujos membros não precisam ser interrompidos na sua vida corrente (como acontece com o telefone), pois a informação fica nos seus endereços disponível, silenciosa, para quando a possam consultar. (JORGE, 2005, p. 148).

Os recursos de comunicação na web proporcionam uma mudança no comportamento dos sujeitos, na forma como se comunicam e no relacionamento que mantêm com o meio, com as pessoas e com a própria tecnologia. 0 padrão tradicional de comunicação é trocado por um mais descontraído - informal, amigável. 0 espaço virtual concede aos sujeitos uma aproximação e flexibilidade que o contato físico muitas vezes não permite. Conforme Melo, Marques e Pinho (2014, p.77), “[...] o bibliotecário necessita desenvolver meios para tornar a biblioteca atraente e indispensável, utilizando-se das tecnologias para atribuir valor à unidade, uma vez que os usuários tendem a distanciarse da biblioteca física ao utilizar a internet." Na realização das atividades de mediação da informação, o bibliotecário deve se aproximar do usuário e manter com ele uma interação, para que possa estabelecer uma comunicação continuada, de modo que seja possível apoiar, auxiliar, mediar, enfim, realizar algum tipo de interferência para o desenvolvimento dos usuários.

Pode-se observar que o usuário da informação é o sujeito que, em determinado momento de sua vida social, identifica a necessidade de buscar a informação, utilizá-la e se apropriar dela. Nessa perspectiva, Sanz Casado (1994, p. 19) define o usuário como “[...] aquele indivíduo que necessita de informação para o desenvolvimento de suas atividades." Assim, os sujeitos que utilizam os serviços e os produtos da biblioteca, em seu ambiente físico ou virtual, são usuários da informação, que recorrem a ela para suprir uma carência ou necessidade de conhecimento, impulsionado, muitas vezes, por eventos da sua realidade social.

Sanz Casado (1994, tradução nossa) divide os usuários da informação em dois grupos: os usuários potenciais, aqueles que necessitam de informação para desenvolver suas atividades, porém não são conscientes disso, e os usuários reais, que, além de ser 
conscientes de que necessitam de informação, utilizam-na com frequência. Assim, tanto os usuários potenciais quanto os reais devem ser contemplados pelas atividades desenvolvidas nas bibliotecas universitárias, às quais cabe desenvolver ações de gestão e mediação da informação e do conhecimento que aproximem e fortifiquem os laços com esses usuários da informação.

O grupo de usuários a ser atendido pelo Bibliotecário 2.0 é composto de jovens estudantes da Geração Y (Net Generation) e, também, de professores da universidade que manifestam o seu próprio comportamento e necessidades. Os estudantes da Geração Y caracterizam-se pela rápida adoção das mídias sociais da Web 2.0, têm participação ativa na Biblioteca Universitária 2.0, enquanto funcionários e professores que desempenham função de pesquisa e ensino, necessitarão desenvolver habilidades para responder e interagir com as mídias sociais que estarão ancorando em todas as áreas do campus [...] (VIEIRA; BAPTISTA; CERVERÓ, 2013, p. 47).

Os usuários da informação que utilizam os produtos e os serviços disponibilizados pelas bibliotecas universitárias, por meio dos dispositivos de comunicação da web social, podem ser os discentes, os docentes e os técnicos, que também utilizam os produtos e os serviços de informação prestados por uma biblioteca universitária em seu ambiente físico. Podem ser jovens nativos digitais ou pessoas de faixa etária mais avançada que desejam incluir-se digitalmente, independentemente de sua classe social, religião, gênero e etnia. Todo sujeito, tendo ou não vínculo com a biblioteca universitária, poderá, potencialmente, ser um usuário da informação nos dispositivos de comunicação da web social disponibilizados pelas bibliotecas universitárias.

A maneira como um usuário da informação se dirige a um bibliotecário no ambiente físico pode ser diferente de como essa ação pode ser realizada no espaço virtual, pois um sujeito pode se sentir inibido no contato presencial, um comportamento que, muitas vezes, não ocorre virtualmente, devido à informalidade dos ambientes virtuais. Nesse sentido, Aguiar (2012, p.108) afirma que “[...] a biblioteca precisa estar onde o usuário está, falar a linguagem da Geração Y e se comunicar por canais diferentes dos tradicionais, ofertando novos serviços e produtos, juntamente com os já existentes $(e$ mail, telefone, formulários etc.).” Uma ação que pode aproximar os usuários dos bibliotecários, por exemplo, é a utilização de uma linguagem mais próxima e comumente adotada pelos usuários nesses dispositivos. 0 uso de uma linguagem mais coloquial por parte dos bibliotecários pode deixar os usuários menos inibidos ao se comunicar com eles. 
O bibliotecário tem a oportunidade de desenvolver e fortalecer uma "parceria" com os usuários que poderá resultar em uma melhoria significativa do desenvolvimento deles e da biblioteca, já que as atividades realizadas por ela são direcionadas aos próprios usuários. Os dispositivos de comunicação da web social apontam meios de ampliar e fortalecer a interação, a participação e a comunicação entre bibliotecários e usuários. Assim, o desenvolvimento da $w e b$ social proporciona visibilidade à cultura participativa $\mathrm{e}$ à necessidade de interação entre os sujeitos no ambiente virtual, o que influencia a realidade e provoca mudanças nos ambientes físicos, inclusive na biblioteca.

A cultura do compartilhamento do conhecimento, da troca de informações e da interação entre os sujeitos, nos dispositivos de comunicação da web social, pode favorecer a cooperação em questões relacionadas à formação acadêmica, à qualificação e ao desenvolvimento de competências em informação. Para Pieruccini (2007, p.11), “[...] sem estruturas socioculturais que lhe dê apoio, sem saber buscar informação, a maioria dos sujeitos perde-se nas tramas do conhecimento, sem condições de apropriar-se nem da memória, nem dos saberes do seu tempo." Dessa maneira, os dispositivos de comunicação da web social podem ser adotados como aliados no apoio à qualificação dos usuários, tanto por meio de ações diretas do bibliotecário quanto pelo incentivo desse profissional e da interação entre os próprios usuários, com troca de experiências e de conhecimentos.

É imprescindível que o bibliotecário, na biblioteca universitária, desenvolva mecanismos de utilização dos dispositivos de comunicação da web social a fim de apresentar aos usuários as atividades que desenvolve e de informar como podem ser utilizados os produtos e os serviços. Marques (2008, p.605) refere que a Internet representa uma "[...] rede de transmissão, formando a maior e mais disseminada rede multiuso do planeta." Os dispositivos de comunicação da web subsidiam o fazer dos bibliotecários e os aproximam mais dos usuários, ao promover a interação para além do ambiente físico da biblioteca. Se os dispositivos de comunicação forem adotados nas bibliotecas universitárias, darão mais visibilidade às atividades desenvolvidas pelos bibliotecários, ampliando as possibilidades de disseminar e acessar a informação.

Vega (2007) afirma que as tecnologias sociais podem ser uma oportunidade para dinamizar as atividades na biblioteca e sua relação com os usuários. Esse autor recomenda que os bibliotecários adotem os serviços baseados na web social, respondendo claramente a três questões: quem será o responsável por administrar os serviços? Que conteúdos serão oferecidos? Para quem será prestado o serviço? Segundo Vega (2007), o 
bibliotecário não deve planejar esses serviços sem prever a recepção favorável dos usuários e sem estabelecer compromissos de participação com eles.

O bibliotecário precisa desenvolver suas atividades de mediação da informação para e com os usuários. É preciso modificar tanto o olhar em relação ao usuário quanto ao próprio acesso à informação, ou seja, a relação entre a informação e o usuário. Rodrigues e colaboradores (2013, p. 86, destaque nosso) alertam que,

Frente à diversidade de atribuições e atuações que lhes cercam, os bibliotecários tentam adequar-se aos novos tempos, substituindo o modelo de biblioteca centrado na disponibilidade, baseado no tamanho da coleção, por um novo modelo centrado na acessibilidade em que prevalece a conexão em rede virtual. Desse modo, buscam novos caminhos para suprir as necessidades de informação do grande público.

Atualmente, devido a questões de agilidade e de conforto, o usuário procura a informação, inicialmente, por meio dos recursos tecnológicos. Os dispositivos de comunicação da web social são fortes aliados na aproximação entre os usuários e a informação de que eles necessitam. É preciso que o bibliotecário desenvolva ações voltadas para a organização, a representação, a disseminação, o acesso e o uso da informação nesses espaços virtuais, a fim de atrair os usuários e mostrar que a biblioteca também está próxima a ele no espaço virtual. Logo, ele pode ter a confiabilidade e o apoio que tem no ambiente físico da biblioteca também no espaço virtual.

O Quadro 1 apresenta alguns dos dispositivos de comunicação da web social, sendo eles o atualmente são mais utilizados pelos sujeitos. Ao analisar o referido quadro, observa-se algumas características desses dispositivos, que os distinguem e que devem ser avaliadas pelos bibliotecários no momento de adoção desses dispositivos, de acordo com o objetivo e atividade de mediação da informação que ele deseja realizar. 
Quadro 1: Principais dispositivos de comunicação da web social

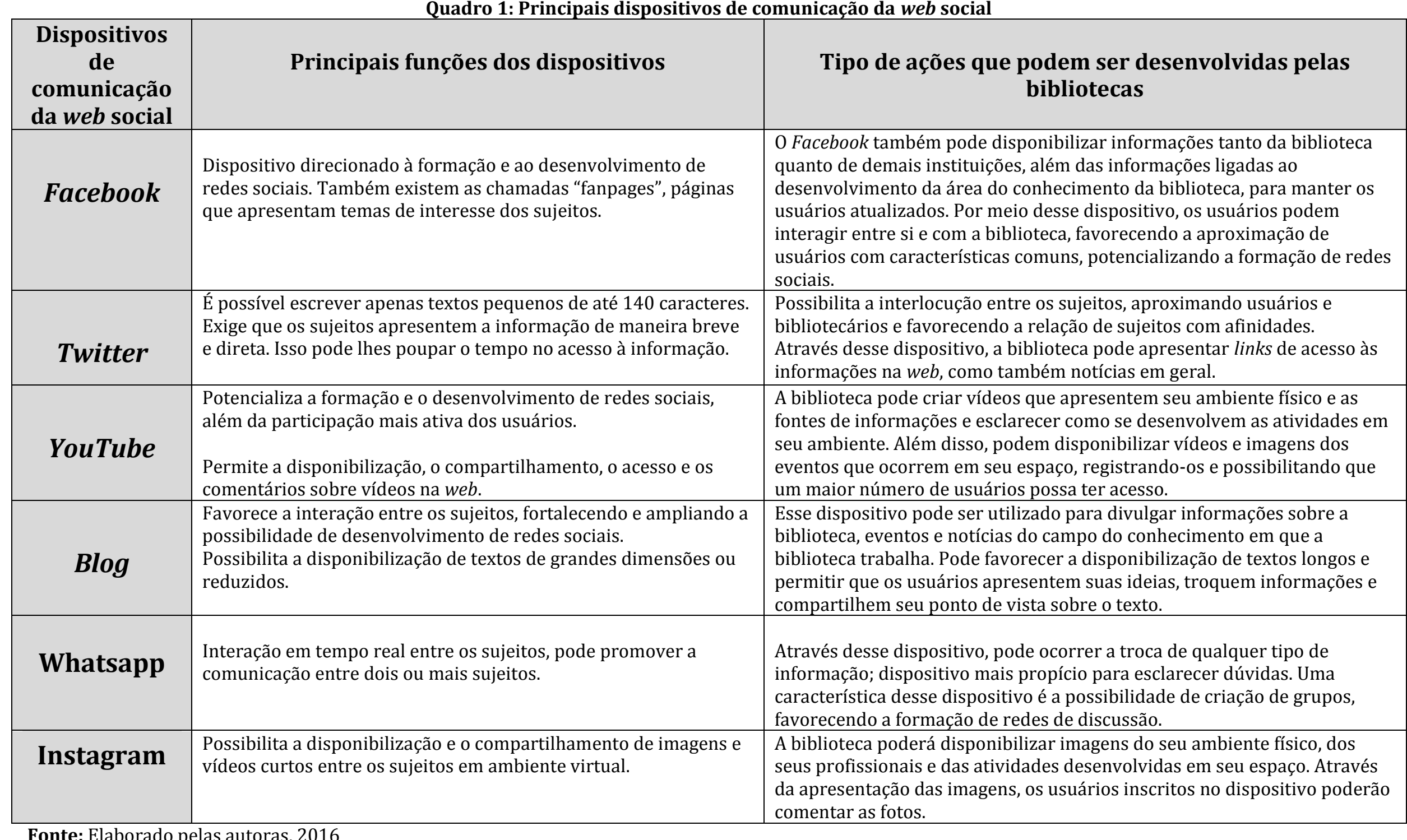

Fonte: Elaborado pelas autoras, 2016 
De acordo com o exposto no Quadro 1, as necessidades dos usuários serão determinantes na escolha do dispositivo de comunicação da web social, pois é por meio da identificação do que os usuários precisam que o bibliotecário planejará as atividades e as ações de mediação da informação que serão realizadas, que compreendem, por exemplo, o tipo e o formato de informações disponibilizadas, a frequência, a organização, a disseminação, a motivação e o incentivo, que estão ligados à interação entre os usuários.

A pesquisa realizada por Santos (2012), cuja amostra foi composta das bibliotecas centrais e/ou sistemas de bibliotecas das universidades brasileiras, constatou que os dispositivos como Twitter, Blog e Facebook são os que mais potencializam a circulação e a apresentação de conteúdos disponibilizados pelas bibliotecas e os dispositivos que mais favorecem a interlocução. Em outra pesquisa, Aguiar (2012, p.97) reafirma os dados identificados por Santos (2012), apresentando como preferência das bibliotecas universitárias a adoção do Facebook, o Twitter e o Blog, como dispositivo de comunicação com os usuários. Assim, embora as bibliotecas universitárias tenham que avaliar seus objetivos e as necessidades dos usuários, a competência dos bibliotecários para usarem os dispositivos, entre outros aspectos determinantes na escolha dos dispositivos de comunicação, elas têm uma tendência a adotar e utilizar esses três dispositivos de comunicação da web social, que são os que mais atendem a esses aspectos.

Outro estudo referente à utilização dos dispositivos de comunicação da web social pelas bibliotecas universitárias foi realizado por Maria, em 2013, que teve como objeto os blogs das bibliotecas universitárias de Portugal. A autora, a partir de sua análise, concluiu que,

Nos blogs analisados, o número de comentários é extremamente reduzido e muito raramente esses comentários merecem uma resposta por parte da equipa editorial. Não existindo interação, não se produz novo conhecimento, nem se acrescenta valor ao já existente, o que é uma das condições da Web 2.0. (MARIA, 2013, p. 147).

A observação feita por Maria (2013) evidencia uma conduta não só de negligência dos bibliotecários - ao deixar de responder aos comentários dos usuários e estabelecer com eles uma comunicação continuada, que poderia ser o início da mediação mais direta da informação - como também da falta a de uma gestão que sistematize as ações nesse ambiente, o que, nesse caso, orientaria o bibliotecário a responder ao comentário do 
usuário e incentivar outros usuários a interagirem a partir do comentário apresentado, ação que Maria (2013) aponta como "acrescentar valor" ao conhecimento existente.

Esse resultado apresentado por Maria (2013) aproxima-se das considerações realizadas por Santos (2012), quando, em sua pesquisa, afirma que o espaço do debate, da troca de informações e da interação entre os usuários, embora venha sendo disponibilizado pelas bibliotecas universitárias, não tem sido potencializado de modo planejado como uma ação efetiva e sistemática da biblioteca para mediar o processo de interlocução em torno da informação. Santos (2012) também reflete que disponibilizar um espaço em que os usuários possam apresentar seus comentários não é suficiente para proporcionar um ambiente convidativo para o debate e a interlocução, pois é preciso que as bibliotecas intensifiquem a disponibilização de conteúdos em diversas abordagens, fortaleçam sua relação com os usuários, convidando-os para participar das discussões nos dispositivos, e transformem esse ambiente em um espaço de exposição de ideias, informações, conhecimentos, sugestões e críticas. Assim, ratifica-se a necessidade de planejar e executar também ações de gestão, por meio das quais o bibliotecário possa incentivar e potencializar a socialização, a cooperação e a interação entre os sujeitos para a construção do conhecimento.

\section{CONSIDERAÇÕES FINAIS}

A biblioteca sofreu alguma alteração em relação à tecnologia de informação e comunicação. As atividades que, antes, tinham um grupo limitado de sujeitos se ampliaram para uma coletividade que, muitas vezes, nem é prevista, o que contribui para atrair usuários potenciais. As atividades de mediação da informação, desenvolvidas nos ambientes físicos das bibliotecas, ganham um novo ambiente para se desenvolver e receber alterações. Os dispositivos de comunicação da web social oferecem uma nova possibilidade de se fazerem as atividades tradicionalmente desenvolvidas nas bibliotecas universitárias em seu ambiente físico, provocando contribuições mútuas, tanto no espaço virtual quanto no físico da biblioteca. Assim, os bibliotecários podem utilizar estratégias que potencializem o espaço de colaboração e atuação dos usuários, favorecendo o desenvolvimento do protagonismo social, ou seja, sujeitos que realizam ações sentem-se e são uma parte ativa do ambiente social e entre eles e a biblioteca, contribuindo ativamente para as ações nesse ambiente. 
Os dispositivos de comunicação da web social contribuem para um novo posicionamento do usuário, que passa a ter uma relação mais ativa com a informação, tanto na busca, no acesso e no uso da informação, quanto na produção de novos conhecimentos. Por meio desses recursos de comunicação na web, o usuário tem mais chances de acessar a informação, não apenas por estar na web, um espaço de grande quantidade de fontes de informação, mas também por receber a colaboração de outros sujeitos, que trocam e indicam informações relevantes.

Outro aspecto é ampliação da interação e a comunicação entre bibliotecários e usuários, por meio desses recursos de comunicação, favorecendo mudanças na aproximação e no fortalecimento dos laços entre o bibliotecário e o usuário e usuário e usuário, como também bibliotecário e equipe da biblioteca. Essa interação é um elemento relevante para uma efetiva comunicação e cooperação entre os sujeitos e para socializar o conhecimento, entre outros aspectos relativos à apropriação da informação, ao desenvolvimento de competências e à construção do conhecimento. 0 bibliotecário pode adotar esse recurso de comunicação na web social para ampliar suas ações de mediação da informação, possibilitando o apoio e o auxílio necessário ao crescimento dos usuários.

Os recursos tecnológicos, especialmente os dispositivos de comunicação da web social, desempenham papel relevante quanto à aproximação entre os sujeitos, ao favorecimento de interação e, principalmente, à relação dinâmica que os sujeitos passam a realizar. Nesse cenário, os sujeitos não são mais dependentes e passivos a determinada ação, mas se comportam de maneira ativa, investigativa e produtora de sua própria modificação e desenvolvimento. A tecnologia apresenta subsídios para a realização dessas ações e esse comportamento, mas são os sujeitos os responsáveis por suas ações. Assim, os dispositivos de comunicação da web social, como qualquer outro recurso tecnológico, não podem ser entendidos como elemento principal, mas como um relevante aliado e facilitador do desenvolvimento do benefício social, e os sujeitos são os verdadeiros determinantes e realizadores de qualquer ação nesse meio.

Nesse sentido, os bibliotecários precisam realizar uma gestão dos dispositivos de comunicação da web social, fazer um planejamento estratégico eficiente pautado em estudos, tanto da necessidade dos usuários relativa aos conteúdos, quanto dos recursos e procedimentos para intensificar o debate e a interação no dispositivo de comunicação. Disponibilizar um espaço em que os usuários possam apresentar seus comentários não é suficiente para proporcionar um ambiente convidativo para o debate e a interlocução, é 
preciso que as bibliotecas intensifiquem a disseminação de conteúdos em diversas abordagens, fortaleçam sua relação com os usuários, convidando-os para participar das discussões nos dispositivos de comunicação. Essa é uma forma de transformar esse ambiente em um espaço de exposição de ideias, informações, conhecimentos, sugestões e críticas.

\section{REFERÊNCIAS}

AGUIAR, Giseli Adornato de. Uso das ferramentas de redes sociais em bibliotecas universitárias: um estudo exploratório na UNESP, na UNICAMP e na USP. 2012. $184 \mathrm{f}$. Dissertação (Mestrado) - Universidade de São Paulo, São Paulo, 2012.

BLATTMANN, Ursula; SILVA, Fabiano Couto Corrêa da. Colaboração e interação na web 2.0 e biblioteca 2.0. Revista ACB: Biblioteconomia em Santa Catarina, Florianópolis, v. 12, n. 2, 2007. Disponível em:< http://revista.acbsc.org.br/index.php/racb/article/view/530/664> Acesso em: 20 set. 2009.

BUFREM, Leilah Santiago; SORRIBAS, Tidra Viana. Mediação e convergência em bibliotecas ACADÊMICAS: saberes e práticas culturais. Enc. Bibli: R. Eletr. Bibliotecon. Ci. Inf., Florianópolis, n. 25, 2008. Disponível em:< https://periodicos.ufsc.br/index.php/eb/article/view/15182924.2008v13n25p68 > Acesso em: 20 set. 2014.

CURTY, Renata Gonçalves. Web 2.0: Plataforma para o conhecimento coletivo. In: TOMAÉL, Maria Inês. Fontes de informação na internet. Londrina: Eduel, 2008. p. 53-78.

FUJITA, Mariângela S. L. Aspectos evolutivos das bibliotecas universitárias em ambiente digital na perspectiva da rede de bibliotecas da UNESP. Inf. \& Soc.: Est., João Pessoa, v. 15, n. 2, p. $97-$ 112, jul./dez. 2005. Disponível em:

<http://www.ies.ufpb.br/ojs/index.php/ies/article/view/33>. Acesso em: 17 set. 2014.

GARCIA, Cristiane Luiza Salazar; ALMEIDA JÚNIOR, Oswaldo Francisco de; VALENTIM, Marta Lígia Pomim. 0 papel da mediação da informação nas universidades. Revista EDICIC, v.1, n.2, p.351-359, Abr./Jun. 2011. Disponível em: <http://www.edicic.org/revista/>. Acesso em: 14 mar. 2010.

GOMES, Henriette Ferreira. 0 ambiente informacional e suas tecnologias na construção dos sentidos e significados. Ciência da Informação, Brasília, v.29, n.1, 2000. Disponível em<http://revista.ibict.br/index.php/ciinf/article/viewArticle/267> . Acesso em: 14 mar. 2010.

GUINCHAT, Claire; MENOU, Michel. Introdução geral às ciências e técnicas da informação e documentação. Brasília: IBICT, 1992.

JORGE, Vítor Oliveira. Informação, comunicação, investigação, inovação, interdisciplinaridade e mediação na sociedade actual - algumas notas prévias a uma antropologia de certos comportamentos contemporâneos. Prisma.com, Porto, n. 2, 2005. Disponível em:< http://revistas.ua.pt/index.php/prismacom/article/view/616>. Acesso em: 12 out. 2014. 
LIMA, Vânia Mara Alves. Terminologia, comunicação e representação documentária. 1998. 118f. Dissertação (Mestrado) - Escola de Comunicação e Artes, Universidade de São Paulo, São Paulo, 1998.

MARIA, Dulce Fernanda Franco. Biblioteca 2.0: produção e organização do conhecimento na internet. 2013. 169f. Dissertação (Mestrado) - Departamento de Ciências da Comunicação, Universidade Lusófona de Humanidades e Tecnologias, Lisboa, 2013.

MARQUES, Rodrigo Moreno. Políticas de informação e comunicação no Brasil: uma análise sob a ótica da razão jurídica. In: COLÓQUIO MEDIAÇÕES E USOS DE SABERES E DA INFORMAÇÃO: um diálogo França - Brasil, 1., 2008, Rio de Janeiro. Anais... Rio de Janeiro: Rede MUSSI, 2008. p. 600- 617.

MELO, Lílian Lima de Siqueira; MARQUES Denílson Bezerra; PINHO, Fabio Assis. A biblioteca universitária e sua atuação frente à mutabilidade de paradigmas. InCID: R. Ci. Inf. e Doc., Ribeirão Preto, v. 5, n. 1, p. 69-89, mar./ago. 2014. Disponível em: < http://www.revistas.usp.br/incid/article/view/64069/pdf_17 >. Acesso em: 12 out. 2014.

PERROTTI, Edmir; PIERUCCINI, Ivete. Infoeducação: saberes e fazeres da contemporaneidade. In: LARA, Marilda L. Ginez de; FUJINO, Asa; NORONHA, Daisy P. (Orgs.). Informação e contemporaneidade: perspectivas. Recife: Néctar, 2007. p. 47-96.

PIERUCCINI, Ivete. Ordem informacional dialógica: mediação como apropriação da informação. In: ENCONTRO NACIONAL DE PESQUISA EM CIÊNCIA DA INFORMAÇÃO, 8., 2007, Salvador. Anais... Salvador: Universidade Federal da Bahia, 2007. 1 CD-ROM.

RAPOSO, Maria de Fátima Pereira; ESPÍRITO SANTO, Carmelita do. Biblioteca universitária proativa. Revista Digital de Biblioteconomia e Ciência da Informação, Campinas, v.4, n.1, p. 87-101, jul./dez. 2006. Disponível em: < http://www.sbu.unicamp.br/seer/ojs/index.php/rbci/article/view/350 >. Acesso em: 20 maio 2014.

RODRIGUES, Mara Eliane Fonseca, et al. A biblioteca e o bibliotecário no imaginário popular. Biblionline, João Pessoa, v. 9, n.1, p.82-95, 2013. Disponível em: <http://www.ies.ufpb.br/ojs/index.php/biblio/article/viewFile/15097/9599>. Acesso em: 20 maio 2014.

SANTOS, Raquel do Rosário. Espaço virtual e a comunicação com os usuários para a mediação da informação: utilização pelas bibliotecas das universidades federais e estaduais brasileiras. 2012. 248 f. Dissertação (Mestrado) - Instituto de Ciência da Informação, Universidade Federal da Bahia, Salvador, 2012.

SANZ CASADO, Elías. Manual de estudios de usuarios. Madrid: Pirámide, 1994.

SHERA, Jesse H. Toward a theory of librarianship and information science. Ciência da Informação, Rio de Janeiro, v.2, n.2, p.87-97, 1973. Disponível em: < http://revista.ibict.br/ciinf/index.php/ciinf/article/view/1643/1251>. Acesso em: 20 maio 2010.

VEGA, José Antônio Merlo. Las tecnologías de la participación en las bibliotecas. Educación y Biblioteca, Espanha, v.19, n. 61, 2007. Disponível em:< http://eprints.rclis.org/bitstream/10760/10558/1/tecnoparti.pdf> Acesso em: 12 jan. 2012. 
VIEIRA, David Vernon; BAPTISTA, Sofi a Galvão; CUEVAS CERVERÓ, Aurora. As competências profissionais do bibliotecário 2.0 no espaço da biblioteca universitária: discussão da prática. Inf. \& Soc.:Est., João Pessoa, v.23, n.2, p. 45-58, maio/ago. 2013.

Recebido em: 04 de março de 2016 Aceito em: 17 de agosto de 2017 